increase in older age groups from 1972 to 1994, which was particularly noticeable in Scottish children. ${ }^{8}$

Although debate over the cut-off points will continue, this should not detract from the urgency of tackling the problem of obesity. Our data indicate that overweight and obesity on the basis of body mass index have increased noticeably since 1984 . Most studies have shown poor prediction of adult obesity from child assessments but a consistent positive correlation between child and adult overweight and obesity. ${ }^{10}$ Rising trends in children will almost certainly be represented in later trends in adult overweight and obesity and probably in an increase in associated adult morbidity.

We thank our colleagues in the study team, all parents, children, and helpers in the study areas, and Professor Tim Cole for supplying the international cut-off points in advance of their publication.

Contributors: SC carried out all the analyses, wrote the first draft of the paper, and is guarantor. RJR was the project leader for the national study of health and growth and initiated and participated in the writing of the paper.
Funding: The national study of health and growth was funded by the Department of Health

Competing interests: None declared.

1 Prentice AM. Body mass index standards for children. BMJ 1998;317:1401-2.

2 Reilly IJ, Dorosty AR, Emmett PM. Prevalence of overweight and obesity in British children: cohort study. BMJ 1999;319:1039.

3 Cole TJ, Bellizzi MC, Flegal KM, Dietz WH. Body mass index in children worldwide: cut-off points for overweight and obesity. BMJ 2000;320:1240-3.

4 Chinn S, Hughes JM, Rona RJ. Trends in growth and obesity in ethnic groups in Britain. Arch Dis Child 1998;78:513-7.

5 Chinn S, Rona RJ. Trends in weight-for-height and triceps skinfold thickness in English and Scottish children 1972-82 and 1982-90. Paediatr Perinatal Epidemiol 1994:8:90-109.

6 Peckham CS, Stark O, Simonite V, Wolff OH. Prevalence of obesity in children born in 1946 and 1958. BMJ 1983; 286:1237-42.

7 Troiano RP, Flegal KM, Kuczmarski RJ, Campbell SM, Johnson CL. Overweight prevalence and trends for children and adolescents. Arch Pediatr Adolesc Med 1995;149:1085-91.

8 Hughes JH, Li L, Chinn S, Rona RJ. Trends in growth in England and Scotland 1972 to 1994 . Arch Dis Child 1997;76:182-9.

9 Cole TJ, Freeman JV, Preece MA. Body mass index reference curves for the UK. Arch Dis Child 1995;73:25-9.

10 Power C, Lake JK, Cole TJ. Measurement and long-term health risks of child and adolescent fatness. Int J Obes Relat Metab Disord 1997;21:507-26. (Accepted 29 September 2000)

\title{
How women with a family history of breast cancer and their general practitioners act on genetic advice in general practice: prospective longitudinal study
}

\author{
Geertruida H de Bock, Christi J van Asperen, Josephine M de Vries, George C H A Hageman, \\ Machiel P Springer, Job Kievit
}

Correspondence to: G H de Bock g.h.de_bock@lumc.nl continued over

BMJ 2001;322:26-7

\section{bri.com}

This article is part of the BMJ's randomised controlled trial of open peer review. Documentation relating to the editorial decision making process is available on the BMJ's website

Genetic advice given by clinical geneticist to general practitioner, based on relative risk of breast cancer calculated for each woman, and advice given by general practitioner to patient. Values are numbers of women

\begin{tabular}{lccccc} 
& \multicolumn{2}{c}{ Relative risk and genetic advice of clinical geneticist } & \\
\cline { 2 - 4 } $\begin{array}{l}\text { Genetic advice given by general } \\
\text { practitioner* }\end{array}$ & $\begin{array}{c}\mathbf{<} ; \\
\text { reassurance }\end{array}$ & $\mathbf{2 - 3 ;}$ surveillance & $\begin{array}{c}\mathbf{2} \text { 3; referral to } \\
\text { family cancer clinic }\end{array}$ & Total \\
\hline Reassurance & 19 & 0 & 0 & 19 \\
\hline Surveillance $\dagger$ & 8 & 17 & 11 & 36 \\
\hline Referral to a family cancer clinic & 0 & 0 & 8 & 8 \\
\hline Total & 27 & 17 & 19 & 63 \\
\hline
\end{tabular}

*All women received advice on breast self examination.

Surveillance=annual palpation by the general practitioner and annual mammography. diseases to be marked and selected. A total of 2000 of the 2220 patients aged between 25 and 50 consulted their general practitioner between April 1994 and July 1995 , and of these 81 sought advice on their familial risk of breast cancer. ${ }^{2}$ These women were subsequently interviewed twice. In summer 1995, 67 of the 81 women were interviewed about their family history of breast cancer. A clinical geneticist reviewed each family history, calculated a relative risk of breast cancer for each woman (from $<2$, representing a normal or slightly increased risk, to $\geqslant 3$, a highly increased risk) and gave genetic advice to the general practitioner (table). The genetic advice was in line with Dutch national guidelines as developed in 1999-2000. In autumn 1995 the general practitioners discussed this advice and the risk assessment with each woman in a single consultation ( $n=63$; four women had moved). In autumn 1998, 42 of the women were asked about their reasons for their compliance (or non-compliance) with the genetic advice and with advice on breast self examination. Data on the genetic advice given by the general practitioner to each patient, the surveillance given by the general practitioner (annual palpation by the general practitioner and annual mammography), and patients' visits to family cancer clinics were extracted from the medical records $(n=63)$. The medical ethics committee of the Leiden University Medical Centre approved the study protocol.

The clinical geneticist's advice was not followed by the general practitioner in $30 \%$ of the individual consultations; the general practitioners advised surveillance more frequently than did the geneticist (table). 
Women appreciated surveillance more than reassurance or referral to a family cancer clinic. Nearly $25 \%$ of the women reported that they performed breast self examination at least monthly. One third of the women were compliant with the advice on surveillance. The main reasons given for non-compliance were not remembering to do preventive activities and a lack of confidence in the value of surveillance.

\section{Comment}

The value of giving genetic advice on breast cancer in primary care is questionable, for three reasons. Firstly, women showed a low level of compliance with genetic advice as given by general practitioners. This is in line with results from other studies on the effectiveness of annual mammography in general practice for asymptomatic women with a family history of breast cancer. ${ }^{3}$ Secondly, there was a low level of compliance among general practitioners with the clinical geneticist's advice. Thirdly, there is no evidence that surveillance is effective in women under $50 .{ }^{45}$ Breast self examination in women under 50 has not been shown to reduce mortality, not even when combined with palpation by a general practitioner, ${ }^{4}$ and the sensitivity of mammography in women without breast symptoms is lower when the women are under $50 .^{5}$ Nevertheless, we believe that there is a place for genetic advice in general practice and that further research could improve its effectiveness.

We thank the general practitioners of the "Wantveld" Health Care Centre for their commitment to the study.

Contributors: GHdB had the original idea for the study, carried out the fieldwork and the analyses, and prepared the manuscript for publication. CJvA assisted in the genetic advice during follow up and helped to prepare the paper for publication. JMdV did the interviewing and helped with the analyses. GCHAH coordinated the contact with the general practitioners and advised on the execution of the study. MPS helped to prepare the paper for publication. JK advised on the analysis and helped to prepare the paper for publication. GHdB is guarantor for the study.

Funding: Leiden University Medical Centre.

Competing interests: None declared.

1 Kinmonth AL, Reinhard J, Bobrow M, Pauker S. The new genetics: implications for clinical services in Britain and the United States. BMJ 1998;316:767-70.

2 De Bock GH, Perk C, Oosterwijk JC, Hageman GCHA, Springer MP, Kievit J. Women worried about their familial breast cancer risk - a study on genetic advice in general practice. Fam Pract 1997;14:40-3.

3 Duijm LE, Guit GL, Zaat JO. Mammographic surveillance of asymptomatic breast cancer relatives in general practice: rate of re-attendance and GP and patient-related barriers. Fam Pract $1997 ; 14: 450-4$

4 16-year mortality from breast cancer in the UK trial of early detection of breast cancer Lancet 1999:353:1909-14.

5 Kerlikowske K, Grady D, Barclay J, Sickles EA, Ernster V. Effect of age, breast density, and family history on the sensitivity of first screening mammography. JAMA 1996;276:33-8.

(Accepted 5 July 2000)
Department of Medical Decision Making, Leiden University Medical Centre, PO Box 9600, 2300 RC Leiden, Netherlands

Geertruida

$\mathrm{H}$ de Bock epidemiologist Job Kievit professor

Department of Clinical Genetics, Leiden University Medical Centre

Christi J van

Asperen

clinical geneticist

Department of General Practice, Leiden University Medical Centre

Josephine M de Vries medical student Machiel P Springer professor

"Wantveld" Health Care Centre, Noordwijk,

Netherlands George C H A Hageman general practitioner

\title{
Raising concerns about family history of breast cancer in primary care consultations: prospective, population based study
}

\author{
Women's Concerns Study Group
}

Following the availability of genetic tests for the genes for breast cancer BRCA1 and 2, genetic centres have reported increasing referral, often of women who are at low risk of breast cancer but who are concerned about their chances of inheriting it, and they have called for better management in primary care. ${ }^{1}$ To inform appropriate management strategies we counted consultations in primary care in which a family history of breast cancer was mentioned. We obtained ethical approval from the Cambridge local research ethics committee.

\section{Population, method, and results}

Nineteen of the 36 partnerships with four or more partners in one health authority were recruited by letter and visit (mean list size 8904 (SD 2231); 74\% training practices). A total of 240 clinicians participated: 152 doctors and 88 nurses, including locums and those working part time.

Each practice collected data over four weeks between August 1997 and July 1998. After all consultations with women aged 16 or older, clinicians recorded the patient's reference number, birth date, mention of a family history of breast cancer or other cancers, breast symptoms, risk of breast cancer, and who first mentioned any of these topics. Consultation data were checked against records of attendance at the practice. Agreement between the patient and clinician on who first mentioned a family history of breast cancer was assessed in a selected subsample of women. These women were invited to participate in a telephone interview by letter (no reminders). Respondents included 39 of 107 women classified as originating discussion of a family history of breast cancer and 33 of a 10\% sample of those classified as not originating such discussions (total 681). Data were double-entered and analysed using STATA 5.0 (Statacorp, College Station, TX).

Eighteen of 19 practices participated, and 20614 of 24269 consultations (85\%) were usable. A sensitivity analysis that assumed that all missing consultations came from the practice with the highest or lowest rate of reporting for a family history of breast cancer gave results within the confidence intervals of the main analysis. No differences in frequency of mentions of family history of breast cancer by clinicians were found over time.

Of the topics recorded, breast symptoms were mentioned in consultation most often, and family his-
Correspondence to: Ann Louise Kinmonth, General Practice and Primary Care Research Unit, University of Cambridge, Cambridge CB2 2SR alk25@medschl. cam.ac.uk

\section{BMJ 2001;322:27-8}

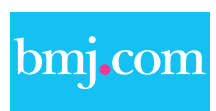

Full details of all authors and their affiliations are on the BMJ's website 